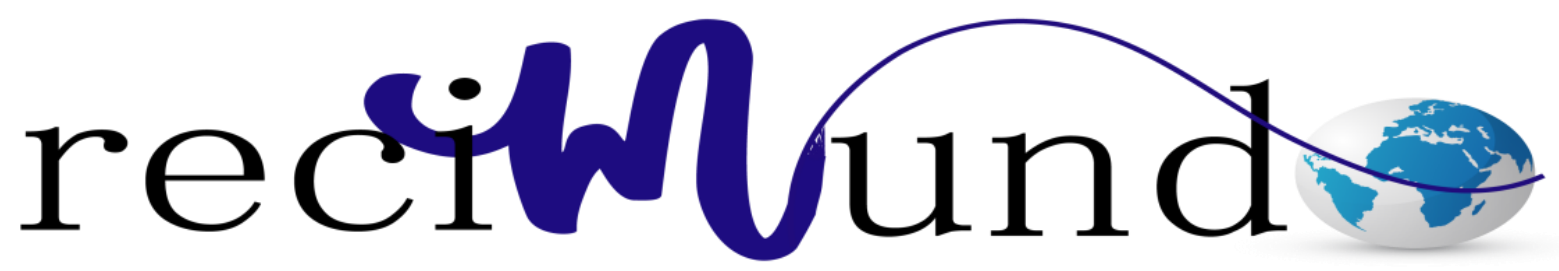

Revista Cientifica Mundo de la Investigación y el Conocimiento

Tatiana Puga-Torres ${ }^{a}$; Xavier Blum-Rojas ${ }^{\text {b }}$; Medardo Blum-Narváez ${ }^{\mathrm{c}}$; Nancy

Sorroza-Rojas $^{\mathrm{d}}$; Nancy Cajas-Flores ${ }^{\mathrm{e}}$; Edith López-Montanero ${ }^{\mathrm{f}}$; Alexandra

Narváez-Sarasti ${ }^{\mathrm{g}}$; Magdalena Aray-Andrade ${ }^{\mathrm{h}}$

Relation between basal sperm morphology and sperm

recovered by swim up

Relación entre la morfología basal de los espermatozoides y los espermatozoides recuperados al nadar

Revista Científica Mundo de la Investigación y el Conocimiento. Vol. 2 núm.3, julio, ISSN: 2588-073X, 2018, pp. 111-123

DOI: 10.26820/recimundo/2.(3).julio.2018.111-123

Editorial Saberes del Conocimiento

Recibido: 05/04/2018

Aceptado: 25/05/2018

Publicado: 30/07/2018

Correspondencia: nancysorroza@uees.edu.ec
a. Innaifest Assited Reproduction Center, Guayaquil, Ecuador.
b. Innaifest Assited Reproduction Center, Guayaquil, Ecuador.
c. Innaifest Assited Reproduction Center, Guayaquil, Ecuador.
d. Universidad Espíritu Santo, Samborondón, Ecuador.
e. Universidad Espíritu Santo, Samborondón, Ecuador.
f. Universidad Espíritu Santo, Samborondón, Ecuador.
g. Universidad Espíritu Santo, Samborondón, Ecuador.
h. Universidad Espíritu Santo, Samborondón, Ecuador. 


\section{Relation between basal sperm morphology and sperm recovered by swim up}

Vol. 2, núm. 3., (2018)

Tatiana Puga-Torres; Xavier Blum-Rojas; Medardo Blum-Narváez; Nancy Sorroza-Rojas; Nancy Cajas-Flores; Edith López-Montanero; Alexandra Narváez-Sarasti; Magdalena ArayAndrade

\section{ABSTRACT}

Objective: The purpose of this study is to investigate a possible correlation between basal sperm morphology and sperm recovered by swim up technique, in patients with fertility problems. Methods: Semen analysis was performed in 112 patients following the laboratory manual for the examination and processing of human semen of the World Health Organization (WHO), fifth edition. Sperm were separated by swim up technique and sperm parameters were reevaluated. Relation between basal sperm morphology and sperm parameters after swim up were evaluated by correlation coefficient analysis. Results: Means of basal parameters were above lower limits established by the WHO. After swim up, the average of sperm recovery, total motility and progressive motility were $8.89 \pm 0.86,91.74 \pm 0.97,97.41 \pm 0.66$ respectively. Sperm parameters after swim up showed an apparently lower concentration of sperm recovered when normal sperm morphology is lower in basal samples; however, these results were not statistically significant. Conclusion: There is no correlation between basal sperm morphology and quality sperm recovered after swim up, despite an apparently lower concentration of sperm after sperm separation is observed in patients with a decreased normal sperm morphology.

Keywords: Sperm morphology, sperm preparation, semen analysis, swim up technique. 


\section{Relation between basal sperm morphology and sperm recovered by swim up}

Vol. 2, núm. 3., (2018)

Tatiana Puga-Torres; Xavier Blum-Rojas; Medardo Blum-Narváez; Nancy Sorroza-Rojas; Nancy Cajas-Flores; Edith López-Montanero; Alexandra Narváez-Sarasti; Magdalena Aray-

Andrade

\section{RESUMEN}

Objetivo: El objetivo de este estudio es investigar una posible correlación entre la morfología basal de los espermatozoides y los espermatozoides recuperados mediante la técnica de natación, en pacientes con problemas de fertilidad. Métodos: Se realizó análisis de semen en 112 pacientes siguiendo el manual de laboratorio para el examen y procesamiento del semen humano de la Organización Mundial de la Salud (OMS), quinta edición. Los espermatozoides fueron separados por la técnica de nadar y los parámetros de los espermatozoides fueron reevaluados. La relación entre la morfología del esperma basal y los parámetros espermáticos después de la inmersión se evaluó mediante el análisis del coeficiente de correlación. Resultados: los promedios de parámetros basales estuvieron por encima de los límites inferiores establecidos por la OMS. Después de nadar, el promedio de recuperación de espermatozoides, motilidad total y motilidad progresiva fueron $8.89 \pm 0.86,91.74 \pm 0.97,97.41 \pm 0.66$ respectivamente. Los parámetros espermáticos después de nadar mostraron una concentración aparentemente menor de espermatozoides recuperados cuando la morfología espermática normal es más baja en las muestras basales; sin embargo, estos resultados no fueron estadísticamente significativos. Conclusión: No existe una correlación entre la morfología basal de los espermatozoides y la calidad de los espermatozoides recuperados después de nadar, a pesar de una concentración aparentemente menor de espermatozoides después de la separación espermática en pacientes con una morfología espermática normal disminuida.

Palabras claves: Morfología espermática, preparación de esperma, análisis de semen, técnica de natación. 


\section{Relation between basal sperm morphology and sperm recovered by swim up}

Vol. 2, núm. 3., (2018)

Tatiana Puga-Torres; Xavier Blum-Rojas; Medardo Blum-Narváez; Nancy Sorroza-Rojas; Nancy Cajas-Flores; Edith López-Montanero; Alexandra Narváez-Sarasti; Magdalena ArayAndrade

\section{Introducción.}

Infertility affects around 60-80 million couples worldwide and the causes can be given by female, male, combined or unknown factors (Avellino, Theva, \& Oates, 2017; Mascarenhas, Flaxman, Boerma, Vanderpoel, \& Stevens, 2012). Male factor affects around $40 \%$ of infertility cases (Avellino et al., 2017), for this reason the evaluation of infertility also involves the male.

Semen analysis implicate the study of macroscopic and microscopic characteristics, where normal and abnormal sperm morphology evaluation are included (World Health Organization, 2010). Different kinds of malformations can be presented in spermatozoa (Chang, Garcia, Hitschfeld, \& Härtel, 2017; Chang, Heutte, Petitjean, Härtel, \& Hitschfeld, 2017; Gatimel, Moreau, Parinaud, \& Léandri, 2017; World Health Organization, 2010), so its evaluation represent an important part for clinical decisions in infertile couple (Badawy, Elnashar, \& Eltotongy, 2009).

In assisted reproduction treatments, sperm separation from seminal fluid is a necessary step to sperm selection; consequently, several techniques for this step have been described (Lampiao \& du Plessis, 2006; Morshedi, Duran, Taylor, \& Oehninger, 2003; Rappa et al., 2016; Urbano, Masson, VerMilyea, \& Kam, 2017; Yamanaka et al., 2016).

Density gradient centrifugation and swim up are the most used sperm separation technique (Lampiao \& du Plessis, 2006; Morshedi, Duran, Taylor, \& Oehninger, 2003; Rappa et al., 2016; Urbano, Masson, VerMilyea, \& Kam, 2017; Yamanaka et al., 2016). Sperm selection by swim-up is based on motility and consequently dependent on sufficient motile sperm in the 


\section{Relation between basal sperm morphology and sperm recovered by swim up}

Vol. 2, núm. 3., (2018)

Tatiana Puga-Torres; Xavier Blum-Rojas; Medardo Blum-Narváez; Nancy Sorroza-Rojas; Nancy Cajas-Flores; Edith López-Montanero; Alexandra Narváez-Sarasti; Magdalena Aray-

Andrade

sample (Thijssen et al., 2014), so it use is recommended in normozoospermic and moderate oligoasthenoteratozoospermic cases (Murcia-Robayo, Jouanisson, Beauchamp, \& Diaw, 2018; Palini et al., 2017). Swim up allows a significant improvement sperm morphology and motility compared with basal parameters (Elberger et al., 2006; Erdem et al., 2009; Kim, Jee, \& Kim, 2015); nevertheless, in some asthenozoospermic cases, sperm recovery is less than expected.

The purpose of this study is to investigate a possible correlation between sperm morphology and sperm recovered by swim up technique in male patients who evaluate their fertility.

\section{Materials and methods}

Study population and semen collection

Men over 18 years old, attended in Innaifest, were included. All volunteers had the conditions for semen collection stablished by the WHO manual, Fifth edition. The Ethics Human Committee of the Kennedy Hospital Group - Ecuador, approved this study.

\section{Semen analysis}

Semen analysis was done one hour after sample collection, following the WHO criteria (fifth edition) for examination and processing of human semen. The microscopic parameters included were sperm concentration $\left(10^{6}\right.$ per $\left.\mathrm{ml}\right)$, total motility (progressive motility motility + non-progressive motility, \%), progressive sperm motility (PR, \%) and sperm morphology (\%). For the staining of sperm was used diff - Quik kit. Normal sperm morphology was evaluated 


\section{Relation between basal sperm morphology and sperm recovered by swim up}

Vol. 2, núm. 3., (2018)

Tatiana Puga-Torres; Xavier Blum-Rojas; Medardo Blum-Narváez; Nancy Sorroza-Rojas; Nancy Cajas-Flores; Edith López-Montanero; Alexandra Narváez-Sarasti; Magdalena ArayAndrade

considering WHO criteria and morphological defects were classified as head defects, neckmidpiece defects and tail defects.

\section{Sperm Preparation}

After semen analysis, sperm were separated by swim up technique, overlaying $1.5 \mathrm{ml}$ of culture medium (global ${ }^{\circledR}$ w/ HEPES with $10 \%$ albumin) above $1 \mathrm{ml}$ of sample. After $60 \sim 90$ minutes of incubation at $37^{\circ} \mathrm{C}$, sperm were taken from the top and centrifuged 10 minutes at 300 g. Samples were reevaluated after swim up.

\section{Statistical Analysis}

The variables were expressed as mean \pm error standard of mean (SEM). Relation between variables were evaluated by correlation coefficient and a $\mathrm{P}$ value of $<0.05$ was considered statistically significant.

\section{Results.}

One hundred twelve patients with age range $20 \sim 57$ years $(34.61+0.63)$ were included. Semen samples were collected with a minimum of two and a maximum of seven days of sexual abstinence $(3.61+0.10)$.

Sperm concentration, total motility and progressive motility were evaluated before and after swim up. Sperm morphology was analyzed only in basal samples. The means of the results are described in table 1. 


\section{Relation between basal sperm morphology and sperm recovered by swim up}

Vol. 2, núm. 3., (2018)

Tatiana Puga-Torres; Xavier Blum-Rojas; Medardo Blum-Narváez; Nancy Sorroza-Rojas; Nancy Cajas-Flores; Edith López-Montanero; Alexandra Narváez-Sarasti; Magdalena Aray-

Andrade

Table 1. Semen parameters before and after swim up

\begin{tabular}{|c|c|c|c|}
\hline & & $\begin{array}{l}\text { Pre - swim up } \\
\text { Mean } \pm \text { SEM }\end{array}$ & $\begin{array}{c}\text { Post - Swim } \\
\text { Mean } \pm \text { SEM }\end{array}$ \\
\hline \multicolumn{2}{|c|}{ Sperm concentration $\left(1^{6}\right.$ per $\left.\mathrm{ml}\right)$} & $47.64 \pm 2.89$ & $8.89 \pm 0.86$ \\
\hline \multicolumn{2}{|c|}{ Total motility (\%) } & $52.83 \pm 1.56$ & $91.74 \pm 0.97$ \\
\hline \multicolumn{2}{|c|}{ Progressive sperm motility (\%) } & $90.45 \pm 0.92$ & $97.41 \pm 0.66$ \\
\hline \multicolumn{2}{|c|}{ Normal sperm morphology } & $13.51 \pm 0.78$ & - \\
\hline \multirow{3}{*}{$\begin{array}{l}\text { Abnormal } \\
\text { sperm } \\
\text { morphology }\end{array}$} & Head & $46.02 \pm 1.16$ & - \\
\hline & Neck-midpiece & $22.62 \pm 0.62$ & - \\
\hline & Tail & $17.30 \pm 0.72$ & - \\
\hline
\end{tabular}

Regarding sperm morphology, table two describes the cases in three groups based on normal sperm morphology and semen parameters after swim up.

Table 2. Normal sperm reference and sperm quality after swim up.

\begin{tabular}{|c|c|c|c|c|}
\hline $\begin{array}{c}\text { Normal } \\
\text { sperm } \\
\text { morphology }\end{array}$ & $\begin{array}{c}\text { Number of } \\
\text { patients }\end{array}$ & $\begin{array}{c}\text { Sperm concentration } \\
\left(\mathbf{1 0}^{\mathbf{6}} \text { per } \mathbf{~ m l}\right)\end{array}$ & $\begin{array}{c}\text { Total } \\
\text { motility (\%) }\end{array}$ & $\begin{array}{c}\text { Progressive } \\
\text { motility (\%) }\end{array}$ \\
\hline$\leq 4 \%$ & 20 & $6.13+1.74$ & $89.75+3.40$ & $96.95+1.49$ \\
\hline $5-14 \%$ & 40 & $7.31+1.05$ & $89.75+1.54$ & $96.57+1.47$ \\
\hline$\geq 14 \%$ & 50 & $11.61+1.50$ & $93.34+1.08$ & $98.26+0.63$ \\
\hline
\end{tabular}




\section{Relation between basal sperm morphology and sperm recovered by swim up}

Vol. 2, núm. 3., (2018)

Tatiana Puga-Torres; Xavier Blum-Rojas; Medardo Blum-Narváez; Nancy Sorroza-Rojas; Nancy Cajas-Flores; Edith López-Montanero; Alexandra Narváez-Sarasti; Magdalena ArayAndrade

Correlation analysis of normal and abnormal sperm morphology with semen parameters after swim up are described in table 3.

Table 3. Correlation coefficient analysis between variables

\begin{tabular}{|l|c|c|c|c|}
\hline \multirow{2}{*}{} & \multicolumn{3}{|c|}{ Sperm morphology } \\
\cline { 2 - 5 } & \multirow{2}{*}{ Normal } & \multicolumn{3}{|c|}{ Abnormal sperm } \\
\cline { 3 - 5 } & & Head & Neck-midpiece & Tail \\
\hline Sperm Concentration (10 $\mathbf{6}$ per ml) & 0.199 & -0.176 & 0.124 & -0.035 \\
\hline Total motility (\%) & 0.160 & -0.080 & 0.026 & -0.054 \\
\hline Progressive motility (\%) & -0.060 & 0.076 & -0.100 & 0.020 \\
\hline
\end{tabular}

\section{Discussion.}

The aim of this study was to evaluate the relation between basal sperm morphology and sperm parameters after swim up. The age range of patients included was 20 57 years. A specific age was not considered as inclusion or exclusion criteria because many patients with fertility problems decide to evaluate their fertility in an intermediate adult age.

Means of semen basal parameters evaluated are over the lower limits established by WHO laboratory manual for the examination and processing of human semen, fifth edition. 


\section{Relation between basal sperm morphology and sperm recovered by swim up}

Vol. 2, núm. 3., (2018)

Tatiana Puga-Torres; Xavier Blum-Rojas; Medardo Blum-Narváez; Nancy Sorroza-Rojas; Nancy Cajas-Flores; Edith López-Montanero; Alexandra Narváez-Sarasti; Magdalena Aray-

Andrade

Several studies such as Eisenberg (2017) reveals the influence of different factors on semen quality as age, finding a decline in semen volume, sperm motility and normal sperm (\%) between men with 30 and 50 years (Eisenberg \& Meldrum, 2017). Other factors such as alcohol consumption as well as diseases like prostate cancer can also negatively affect spermatogenesis and semen quality; (E. Ricci et al., 2017; Sigman, 2017). On the other hand, it has been suggested that racial differences exist in semen quality at the time of infertility evaluation (Khandwala et al., 2017).

Sperm morphology allows to clarify the potential fertility of semen samples (Avellino et al., 2017). the most common classification system used is the WHO criteria (Badawy et al., 2009); however, we still find a wide variety of morphology evaluation technique (Yamanaka et al., 2016). Further, morphology evaluation depends on the experience of the evaluator (MurciaRobayo et al., 2018); therefore, the subjective nature of this evaluation makes it difficult to compare the results with the parameters established by the WHO (Yamanaka et al., 2016).

There are several techniques of sperm separation in assisted reproduction, being gradient and swim up the most used. In the present work, direct swim up with final centrifugation of supernatant was used. One hundred and twelve samples were processed, with not sperm recovery in two samples.

Swim up technique is based on motility and consequently dependent on a sufficient number of motile spermatozoa in the sample (Ramos et al., 2015), sperm recovery is less than other techniques of sperm separation but sperm isolated have better motility (Morshedi et al., 2003; G. Ricci et al., 2009; Yamanaka et al., 2016). This is consistent with our results, where 


\section{Relation between basal sperm morphology and sperm recovered by swim up}

Vol. 2, núm. 3., (2018)

Tatiana Puga-Torres; Xavier Blum-Rojas; Medardo Blum-Narváez; Nancy Sorroza-Rojas; Nancy Cajas-Flores; Edith López-Montanero; Alexandra Narváez-Sarasti; Magdalena ArayAndrade

average of sperm recovery, total motility and progressive motility after swim up were $8.89 \pm$ $0.86,91.74 \pm 0.97,97.41 \pm 0.66$ respectively.

Concerning the two samples in which sperm were not recovered after swim up, we are not clear about the cause of it. Samples were processed in the same way as the other samples because they had the required criteria. In both cases, basal parameters of sperm concentration, total motility and progressive sperm motility were found over the lower limits established by the WHO; nevertheless, one case had normal sperm morphology below this limit (3\%) and the other case was in borderline (6\%). It is described that swim up as well as the gradient technique is indicate in normospermia or moderate oligoasthenoteratozoospermia cases (Palini et al., 2017); nevertheless, in samples with minor and moderate teratozoospermia can be obtained an acceptable number of functional sperm recovery (count $10^{6} \mathrm{x}$ motility $\% \mathrm{x}$ normal morphology \%) after swim up (Correa-Pérez, Fernández-Pelegrina, Córdova-Claudio, Kaskar, \& Panayiotis, 2003).

Patients were divided in three groups, considering normal sperm morphology: $\leq 4 \%$, $5-14 \%$ and $>14 \%$. An apparently lower concentration of sperm recovery after swim up in patients with normal sperm $\leq 4 \%$ and between $5 \sim 14 \%$ was observed; however, these results were not statistically significant. In the same way, no relationship was found between specific sperm abnormalities (head, neck-midpiece and tail) and parameters of the samples after swim up. Our results are consistent with G. Ricci (2009), who reported that any basal semen parameters are an independent predictor to determine the recovery rate of progressive motility sperm. 


\section{Relation between basal sperm morphology and sperm recovered by swim up}

Vol. 2, núm. 3., (2018)

Tatiana Puga-Torres; Xavier Blum-Rojas; Medardo Blum-Narváez; Nancy Sorroza-Rojas; Nancy Cajas-Flores; Edith López-Montanero; Alexandra Narváez-Sarasti; Magdalena Aray-

Andrade

\section{Conclusion}

There is no correlation between basal sperm morphology and quality sperm recovered after swim up, despite an apparently lower concentration of sperm after sperm separation is observed in patients with a decreased normal sperm morphology.

\section{References}

Avellino, G., Theva, D., \& Oates, R. D. (2017). Common urologic diseases in older men and their treatment: how they impact fertility. Fertil Steril, 107(2), 305-311. doi:10.1016/j.fertnstert.2016.12.008

Badawy, A., Elnashar, A., \& Eltotongy, M. (2009). Effect of sperm morphology and number on success of intrauterine insemination. Fertil Steril, 91(3), 777-781. doi:10.1016/j.fertnstert.2007.12.010

Chang, V., Garcia, A., Hitschfeld, N., \& Härtel, S. (2017). Gold-standard for computer-assisted morphological sperm analysis. Comput Biol Med, 83, 143-150. doi:10.1016/j.compbiomed.2017.03.004

Chang, V., Heutte, L., Petitjean, C., Härtel, S., \& Hitschfeld, N. (2017). Automatic classification of human sperm head morphology. Comput Biol Med, 84, 205-216. doi:10.1016/j.compbiomed.2017.03.029

Correa-Pérez, J., Fernández-Pelegrina, R., Córdova-Claudio, M., Kaskar, K., \& Panayiotis, Z. (2003). Improvement of morphological deficiencies according to the degree of teratozoospermia: Is it possible to reach a comparable to normozoospermic semen specimen? Paper presented at the ASRM, United State.

Eisenberg, M. L., \& Meldrum, D. (2017). Effects of age on fertility and sexual function. Fertil Steril, 107(2), 301-304. doi:10.1016/j.fertnstert.2016.12.018

Elberger, L., Grünwaldt, M. M., ivita, A. D., Arenas, G., Buxeda, P. S., \& Fried, E. P. d. (2006). Sperm morphology before and afert capacitation. Paper presented at the ASRM, United States.

Erdem, A., Erdem, M., Gumuslu, S., Kulak, D., Oktem, M., \& Karabacak., O. (2009). Sperm morphology before and after sperm preparation do not predict pregnancy in intrauterine insemination (IUI) cycles with husband sperm. Paper presented at the ASRM, United States. 


\section{Relation between basal sperm morphology and sperm recovered by swim up}

Vol. 2, núm. 3., (2018)

Tatiana Puga-Torres; Xavier Blum-Rojas; Medardo Blum-Narváez; Nancy Sorroza-Rojas; Nancy Cajas-Flores; Edith López-Montanero; Alexandra Narváez-Sarasti; Magdalena ArayAndrade

Gatimel, N., Moreau, J., Parinaud, J., \& Léandri, R. D. (2017). Sperm morphology: assessment, pathophysiology, clinical relevance, and state of the art in 2017. Andrology, 5(5), 845862. doi:10.1111/andr.12389

Khandwala, Y. S., Zhang, C. A., Li, S., Behr, B., Guo, D., \& Eisenberg, M. L. (2017). Racial Variation in Semen Quality at Fertility Evaluation. Urology, 106, 96-102. doi:10.1016/j.urology.2017.03.064

Kim, S. K., Jee, B. C., \& Kim, S. H. (2015). Histone methylation and acetylation in ejaculated human sperm: effects of swim-up and smoking. Fertil Steril, 103(6), 1425-1431. doi:10.1016/j.fertnstert.2015.03.007

Lampiao, F., \& du Plessis, S. S. (2006). Comparing the Multi-ZSC one-step standardized swimup method to the double-wash swim-up method with regard to the effects of sperm separation on morphology, head morphometry, and acrosome reaction inducibility. Fertil Steril, 86(3), 739-741. doi:10.1016/j.fertnstert.2006.02.084

Mascarenhas, M. N., Flaxman, S. R., Boerma, T., Vanderpoel, S., \& Stevens, G. A. (2012). National, regional, and global trends in infertility prevalence since 1990: a systematic analysis of 277 health surveys. PLoS Med, 9(12), e1001356. doi:10.1371/journal.pmed.1001356

Morshedi, M., Duran, H. E., Taylor, S., \& Oehninger, S. (2003). Efficacy and pregnancy outcome of two methods of semen preparation for intrauterine insemination: a prospective randomized study. Fertil Steril, 79 Suppl 3, 1625-1632.

Murcia-Robayo, R. Y., Jouanisson, E., Beauchamp, G., \& Diaw, M. (2018). Effects of staining method and clinician experience on the evaluation of stallion sperm morphology. Anim Reprod Sci, 188, 165-169. doi:10.1016/j.anireprosci.2017.11.021

Palini, S., Stefani, S., Primiterra, M., Benedetti, S., Barone, S., Carli, L., . . . Feichtinger, W. (2017). Comparison of in vitro fertilization outcomes in ICSI cycles after human sperm preparation by density gradient centrifugation and direct micro swim-up without centrifugation. JBRA Assist Reprod, 21(2), 89-93. doi:10.5935/1518-0557.20170022

Ramos, V. B., Cipriani, D. a. C., Araújo, E. S., Salvador, R. A., Senn, A. P., Frajblat, M., \& Amaral, V. L. (2015). Sperm Selection Using Three Semen Processing Techniques. JBRA Assist Reprod, 19(4), 223-226. doi:10.5935/1518-0557.20150043

Rappa, K. L., Rodriguez, H. F., Hakkarainen, G. C., Anchan, R. M., Mutter, G. L., \& Asghar, W. (2016). Sperm processing for advanced reproductive technologies: Where are we today? Biotechnol Adv, 34(5), 578-587. doi:10.1016/j.biotechadv.2016.01.007 


\section{Relation between basal sperm morphology and sperm recovered by swim up}

Vol. 2, núm. 3., (2018)

Tatiana Puga-Torres; Xavier Blum-Rojas; Medardo Blum-Narváez; Nancy Sorroza-Rojas; Nancy Cajas-Flores; Edith López-Montanero; Alexandra Narváez-Sarasti; Magdalena Aray-

Andrade

Ricci, E., Al Beitawi, S., Cipriani, S., Candiani, M., Chiaffarino, F., Viganò, P., . . Parazzini, F. (2017). Semen quality and alcohol intake: a systematic review and meta-analysis. Reprod Biomed Online, 34(1), 38-47. doi:10.1016/j.rbmo.2016.09.012

Ricci, G., Perticarari, S., Boscolo, R., Montico, M., Guaschino, S., \& Presani, G. (2009). Semen preparation methods and sperm apoptosis: swim-up versus gradient-density centrifugation technique. Fertil Steril, 91(2), 632-638. doi:10.1016/j.fertnstert.2007.11.068

Sigman, M. (2017). Introduction: What to do with older prospective fathers: the risks of advanced paternal age. Fertil Steril, 107(2), 299-300. doi:10.1016/j.fertnstert.2016.12.020

Thijssen, A., Klerkx, E., Huyser, C., Bosmans, E., Campo, R., \& Ombelet, W. (2014). Influence of temperature and sperm preparation on the quality of spermatozoa. Reprod Biomed Online, 28(4), 436-442. doi:10.1016/j.rbmo.2013.12.005

Urbano, L. F., Masson, P., VerMilyea, M., \& Kam, M. (2017). Automatic Tracking and Motility Analysis of Human Sperm in Time-Lapse Images. IEEE Trans Med Imaging, 36(3), 792801. doi:10.1109/TMI.2016.2630720

World Health Organization, D. o. R. H. a. R. (2010). WHO laboratory manual for the examination and procesing of human semen. In W. H. Organization (Series Ed.), W. H. Organization (Ed.), (pp. 287).

Yamanaka, M., Tomita, K., Hashimoto, S., Matsumoto, H., Satoh, M., Kato, H., . . Morimoto, Y. (2016). Combination of density gradient centrifugation and swim-up methods effectively decreases morphologically abnormal sperms. J Reprod Dev, 62(6), 599-606. doi:10.1262/jrd.2016-112 